\title{
Communications
}

\section{A Method for Determining the Distribution of Cationic Shrink-resist Resins on Wool}

\author{
J. GARCIA-DOMINGUEZ \\ M. R. JULIA \\ A. de la MAZA \\ J. M. PUJOL and \\ J. SANCHEZ
}

Instituto Tecnologia Quimica y Textil

Patronato 'Juan de la Cierva'

Barcelona

Spain

\section{T. SHAW}

International Wool Secretariat

Valley Drive

Ilkley

Yorkshire LS29 8PB

$A$ method for determining the distribution of cationic shrink-resist resins on wool has been developed. The method is based on a staining technique, using an anionic fluorescent brightening agent (FBA) under specific conditions in which the FBA stains the cationic resin in pre-

ference to the wool. When the stained samples are observed under ultraviolet radiation by means of the optical microscope, the areas on the wool fibres where resin is located fluoresce, whereas areas free from resin appear dark. The technique is simple and rapid, and enables the regularity of deposition of cationic resins on wool to be followed when the various parameters which play a role in the pretreatment of the fibre and the application of resins are changed. Regularity of resin deposition is important in the achievement of high levels of shrink-resistance in treated fabrics.

\section{Introduction}

The examination of resin-treated fibre assemblies for evenness of distribution of resin is of great technological importance. Ideally, a resin should be distributed homogeneously throughout the fibre assembly. If processing conditions are adjusted to give a more even distribution of resin, it will usually be found that less resin is required to give the desired effect and any deleterious effects associated with the treatment are minimized.

Resin treatment of cellulosic fibres to give crease-resist or easy-care finishes is far older than resin treatment of wool to give shrink-resistance, and staining methods for the detection of aminoplast resins on cotton have been available for many years [1]. Recently, Miro et al. [2] developed an improved staining technique for resin-treated cotton, using a fluorescent brightening agent, and they related the intensity of staining

*Presented at the IWTO Technical Committee Meeting, Paris, December 1974 both to the degree of crosslinking and to the degree of swelling in the treated fibres.

One of the most important of the shrink-resist resin processes for wool is the chlorination-Hercosett (Hercules Chemical Co.) process [3], which is most commonly applied either to tops in a continuous process, or to knitted garments by an exhaust process from a long liquor. The Hercosett resin is a strongly cationic polyamide-epichlorohydrin polymer, and, under appropriate conditions; the resin can be stained with anionic dyes preferentially to the wool to which it is applied [4]. However, this method of staining gives insufficient contrast to reveal the detailed distribution of the resin on the fibre, so a more sensitive stain would be of great interest. At the same time, any new staining method should be simple and should require a minimum of special apparatus if it is to be of use outside the research laboratory.

This paper describes the development of a staining method designed to meet these requirements, and the application of the method to wool tops and fabrics treated by the chlorination-Hercosett resin process under industrial and laboratory conditions.

Experimental

\section{CHEMICALS}

The following proprietary products were obtained from their manufacturers:

Hercosett 57 (Hercules Chemical Co.), a polyamideepichlorohydrin resin, $10 \%$ active aqueous solution

Oligan SW (CGY), a polythiol shrink-resist resin, $40 \%$ active aqueous emulsion

Catalyst 3774 (CGY), a cationic coreactant resin for use with Oligan SW, $20 \%$ active aqueous solution

Melafix CH (CGY), a nitrogenous chlorine-retarding agent FiClor Clearon (Fisons Industrial Chemicals Ltd), sodium dichloroisocyanurate dihydrate, containing $55 \%(\mathrm{wt} / \mathrm{wt})$ available chlorine

Blancophor BA (BAY), an anionic stilbene fluorescent brightening agent (C.I. Fluorescent Brightener 113)

Triton X-100 (Rohm \& Haas), a nonylphenol-ethylene oxide condensate, nonionic wetting agent

All other chemicals were of laboratory-reagent grade or were readily available commercial products.

\section{TEXTILE MATERIALS}

Chlorine-Hercosett-treated Tops

Merino $64 \mathrm{~s}$ top treated industrially by the continuous chlorine-Hercosett process was used. Approximately $2 \%$ available chlorine was used in pretreatment and $2 \%$ Hercosett 57 (resin solids) was applied to the chlorinated wool.

Chlorine-Hercosett-treated Woven Fabric

A plain weave botany worsted fabric was used. The fabric was 
chlorinated batchwise at a wool:liquor ratio of $1: 30$. The bath was set with $1 \%$ Melafix $\mathrm{CH}$ and $0.3 \mathrm{~g} / 1$ Triton $\mathrm{X}-100$, adjusted to $\mathrm{pH} 2$ with $\mathrm{HCl}$, and the fabric entered. Sodium hypochlorite was added to give $1.5 \%$ available $\mathrm{Cl}_{2}$ (o.w.w.)* and chlorination was allowed to proceed at $20^{\circ} \mathrm{C}$ for $15 \mathrm{~min}$. The wool was next given an antichlor treatment with $2 \%$ sodium metabisulphite, then neutralized using $1 \%$ sodium carbonate, and finally rinsed. Hercosett treatment was carried out by padding the fabric to $100 \%$ wet pick-up through a solution containing 2\% (wt/vol.) Hercosett 57 (resin solids) adjusted to $\mathrm{pH} 6.5$ with sodium bicarbonate. Finally, the samples were dried at $80^{\circ} \mathrm{C}$.

\section{Chlorine-Hercosett-treated Knitted Fabrics}

A plain Shetland fabric was used, composed of $2 / 8$ s w.c. $\dagger$ (R220/2 tex) yarns knitted to cover factor 0.9 worsted units (9.9 tex units). The fabric was wetted and the bath adjusted to pH 3.5 with acetic acid (wool:liquor ratio 1:30). FiClor Clearon was added over $15 \mathrm{~min}$ to give $1.1 \%, 2.2 \%$ or $3.3 \%$ Clearon o.w.w. $\left(0.6 \%, 1.2 \%\right.$ or $1.8 \% \mathrm{Cl}_{2}$ o.w.w.) and chlorination continued at $20^{\circ} \mathrm{C}$ until the bath was exhausted. Antichlor treatment was carried out with $3 \%$ sodium metabisulphite for $10 \mathrm{~min}$. Hercosett 57 ( $2 \%$ resin solids o.w.w.) was added over $5 \mathrm{~min}$, the bath temperature was increased to $30^{\circ} \mathrm{C}$ and the $\mathrm{pH}$ adjusted with ammonia to $\mathrm{pH} \mathrm{7-8.}$ Hercosett exhaustion was continued for a further $20 \mathrm{~min}$, and the samples were finally dried at $80^{\circ} \mathrm{C}$.

One sample was deliberately chlorinated unevenly by using a bath at $30^{\circ} \mathrm{C}$ set at $\mathrm{pH} 1.5$ with hydrochloric acid, and adding $2.2 \%$ FiClor Clearon o.w.f. (1.2\% $\mathrm{Cl}_{2}$ o.w.w.) all at once, rather than slowly over a period of $15 \mathrm{~min}$. The remaining details of the treatment were as described above.

\section{Oligan SW-treated Woven Fabric}

Fabrics were treated by padding to $100 \%$ wet pick-up with Oligan SW (3.5\% resin solids o.w.w.), Catalyst 3774 (0.35\% active constituent o.w.w.) and sodium carbonate (1\% o.w.w.). In laboratory treatments, a botany afghalaine fabric was used, and the fabric was dried horizontally on a pin-frame at $40^{\circ} \mathrm{C}$ for $2 \mathrm{~h}$. A woollen tartan fabric was treated industrially, and this was dried in a multilayer tenter at $120^{\circ} \mathrm{C}$.

\section{PROCEDURE}

\section{Staining}

A $0.3-\mathrm{g}$ wool sample was treated with stirring in a $160-\mathrm{ml}$ bath containing $1 \%$ (wt/vol.) of Blancophor BA adjusted to $\mathrm{pH} \mathrm{8-9}$ by addition of sodium carbonate. During the 40 -min staining period, the temperature was carefully controlled at $0-1^{\circ} \mathrm{C}$. Accurate temperature control was essential for maximum staining contrast. After staining, the sample was rinsed with distilled water until all unfixed FBA was removed, and then dried at room temperature.

\section{Photography}

Treated and stained fabrics and tops were irradiated with an ultraviolet source (Sylvania Tube, type F15T8 B.L.B.) and photographed directly using a Minolta SRT 101 reflex camera fitted with an ultraviolet filter (Wild type GG13C). Exposure

* o.w.w. = on weight of wool

$\dagger$ w.c. $=$ worsted count was for $0.25 \mathrm{~s}$ at $\mathrm{f} 8$, using Kodak Plus X panchromatic fil (125ASA).

\section{Photomicrography}

Photomicrography of stained yarns and fibres was carried out using a Wild M-20 optical microscope fitted with a Wild MKa 1 camera back. A high-pressure mercury source (Wild, type HBO 200) was used for illumination. The incident light was filtered through a heat filter (KG 1), two ultraviolet-exciting filters (UG 1) and finally a red absorption filter (BG 38). An ultraviolet filter type GG13C, was placed in the eyepiece of the microscope and Kodak VP 120 film (120ASA) was used with an exposure time of $30 \mathrm{~s}$.

\section{Felting Shrinkage Test}

A load of $1 \mathrm{~kg}$ of samples plus knitted polyester makeweight was agitated in a 50-1 International Cubex Machine containing 151 of $\mathrm{pH} 71-\mathrm{M}$ phosphate buffer at $40^{\circ} \mathrm{C}$. The dimensions of the samples were measured after $5 \mathrm{~min}$ and $185 \mathrm{~min}$ agitation and area felting shrinkage was taken as the difference in area of the samples between these two agitation times.

\section{Results and Discussion}

\section{RESIN DISTRIBUTION IN CHLORINE-HERCOSETT TREATED TOP}

Figure 1 illustrates the effect of staining with FBA on two tops, one of which was chlorinated only (Figure 1a), whilst the
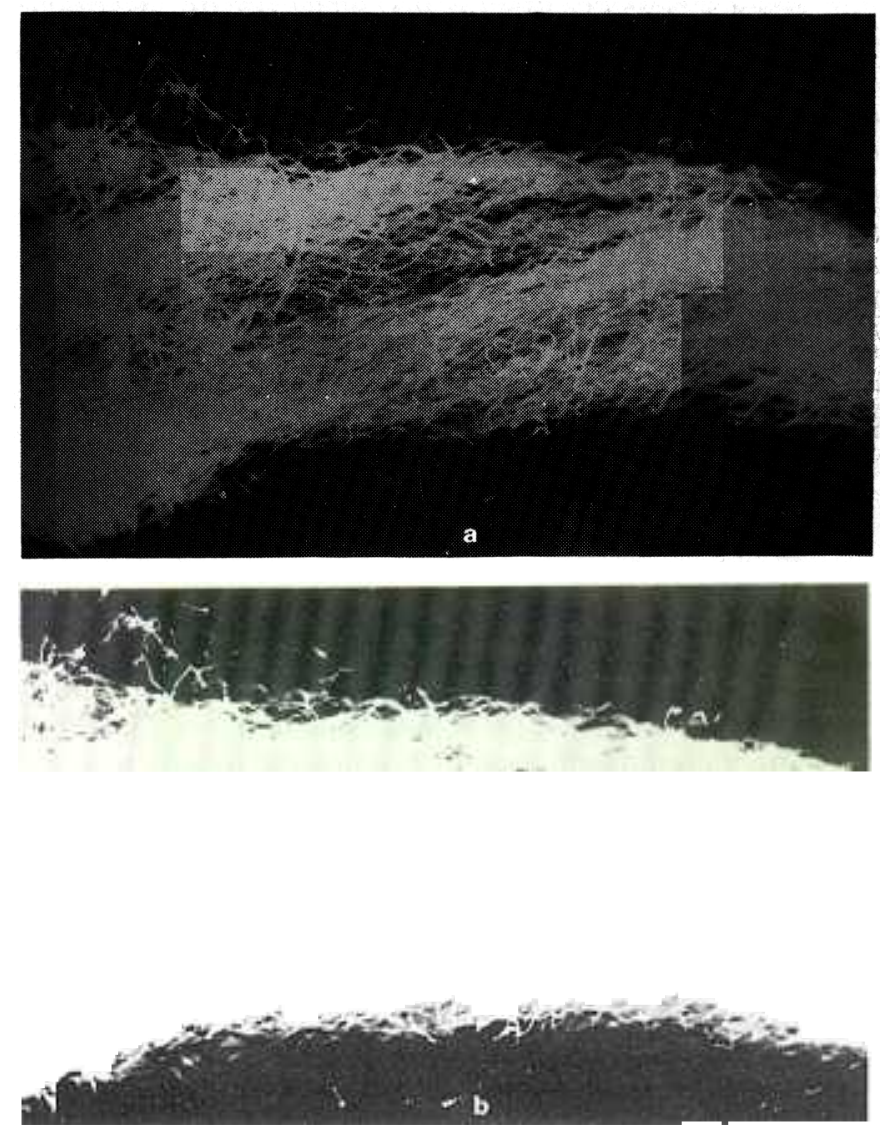

Figure 1.- FBA-stained tops viewed under ultraviolet radiation: (a) chlorinated top and (b) chlorine-Hercosett treated top 
other was treated by the chlorine-Hercosett process (Figure 1b). Under the conditions chosen for staining, fluorescence was entirely absent in the chlorinated top, but was intense and uniform in the chlorine-Hercosett-treated top. An untreated top gave a similar result to the chlorinated top, thus demonstrating that the strongly cationic resin was responsible for the uptake of FBA.

A layer of fibres removed from the outside of a chlorineHercosett-treated top after staining showed the same level of fluorescence as did the whole top (Figure 2a), but when fibres removed from the inside of the top were examined, it was seen that the intensity and uniformity of fluorescence were both reduced (Figure 2b). To demonstrate that this reduction in fluorescence was not due to uneven penetration of the FBA during the staining process, layers of the internal part of the top were taken before staining, and the staining process with
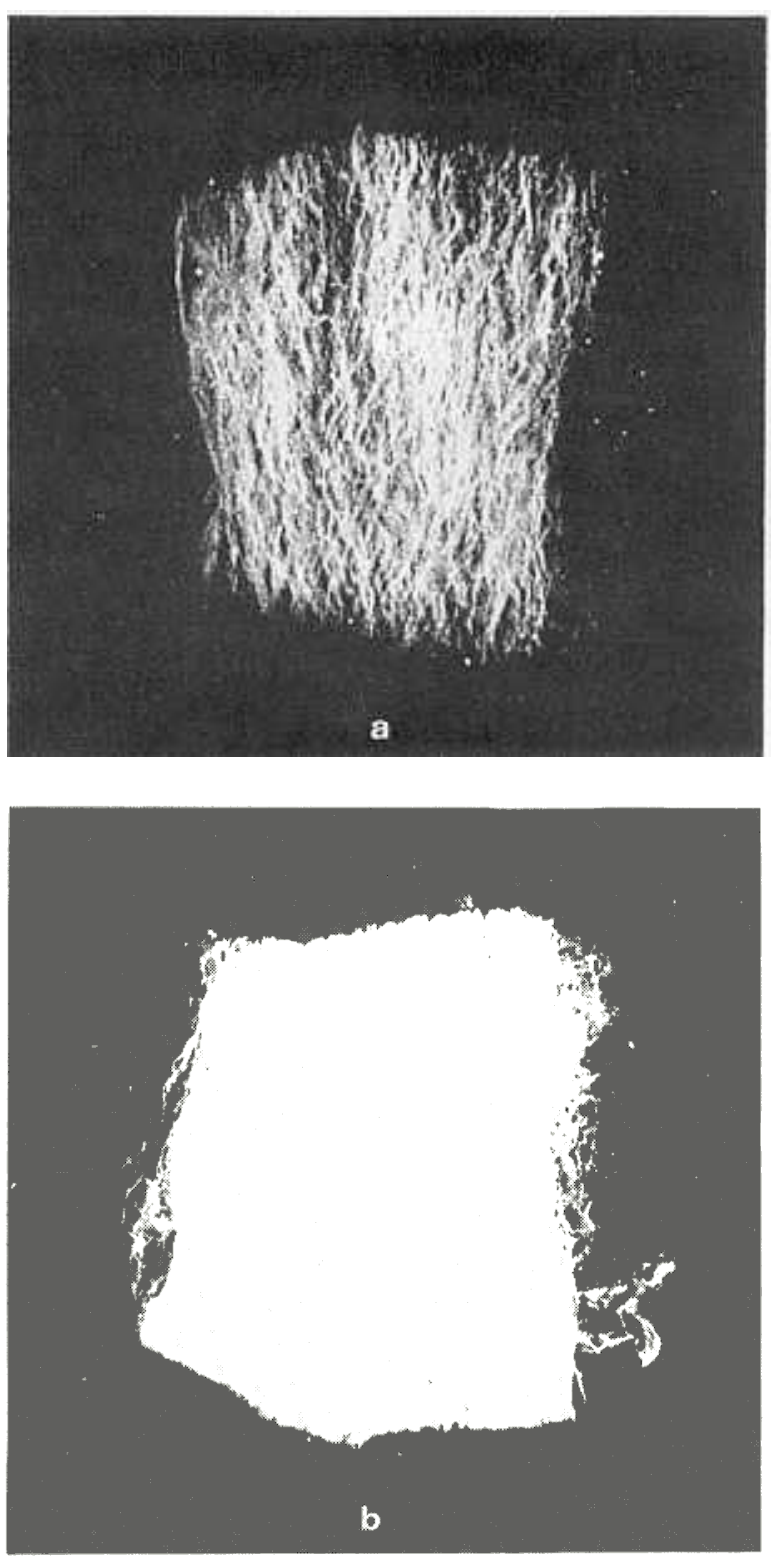

Figure 2 - Fibre layers removed from FBA-stained, chlorineHercosett-treated top viewed under ultraviolet radiation. (a) fibres from exterior and (b) fibres from interior of top
FBA carried out separately on each sample under the same conditions. In this case also, fibres from the inside of the top showed less fluorescence than those from the outside.

The appearance under the microscope of individual stained fibres taken from the inside and the outside of a chlorineHercosett-treated top is illustrated in Figures $3 \mathrm{a}$ and $3 \mathrm{~b}$. The overall level of fluorescence of the fibre from the exterior region of the top was higher and almost all parts of the fibre showed some fluorescence. By contrast, parts of the fibre from the interior of the top showed no fluorescence, whilst other portions showed very weak fluorescence. Twenty-five individual fibres taken from the exterior and from different levels within the interior mass of the top, and examined along their whole length, gave results which agreed with the pattern shown in Figure 3.
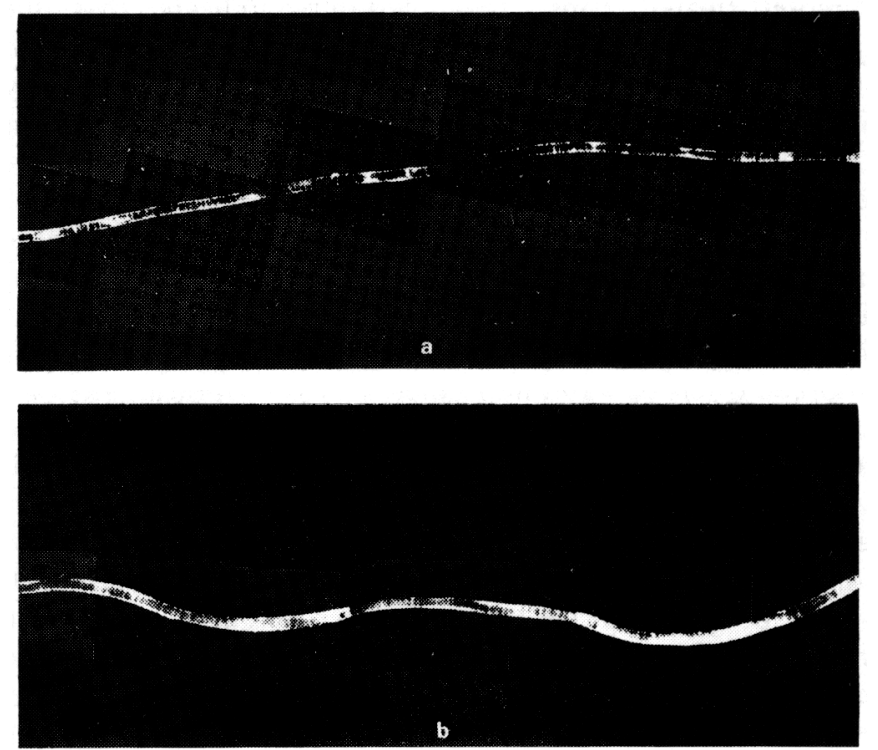

Figure 3 - Photomicrographs of single fibres removed from FBA-stained chlorine-Hercosett-treated top viewed under ultraviolet radiation. (a) fibre from interior and (b) fibre from exterior of top

Figures 1-3 demonstrate the great contrast between treated and untreated wool fibres obtainable with this staining method, as well as the great sensitivity of the technique, which is capable of revealing resin distribution to such a fine degree that, in Figure 3a for example, fluorescent-stained resin can be seen to be more heavily deposited at scale margins than on the remainder of the fibre surface.

Whether the lack of uniformity of resin distribution in chlorine-Hercosett-treated top is a consequence of unlevel chlorination or of lack of penetration of resin to the interior of the chlorinated top remains an open question, but further experiments, described later in this paper, suggest that levelness of chlorination may be the controlling influence.

To some extent, distribution of Hercosett resin observed here is at variance with the results of previous workers. Anderson et al. $[5,6]$ examined fibres from chlorine-resintreated tops in the scanning electron microscope and concluded that, in successful treatments, the whole of each fibre surface was sheathed in resin. Makinson and Lead [7] came to the same conclusion after examination, by optical microscopy, 
of sheaths of resin obtained by dissolution of wool from a treated top. However, unlike the technique described here, neither of the methods used by these previous workers was capable of giving an overall impression of the distribution of resin in a treated top. It is often extremely difficult to tell from scanning electron micrographs whether a fibre is coated with resin or not, and the interpretation of the illustrations in references [5] and [6] certainly gives rise to some doubts in this respect. In the work of Makinson and Lead [7], the longest resin tubes isolated were $1 \mathrm{~mm}$ in length, and cannot be construed as evidence of complete sheaths of resin covering each fibre. However, it is possible that fragmentation of the tubes occurred during their preparation, so their short length is not a proof of a discontinuous film of resin.

Even if the results presented here do not prove unequivocally that there are uncoated segments of fibre in Hercosett-treated tops, they certainly indicate that the distribution of resin is less level than might be inferred from previous work in this field. However, the conclusion that many fibres from treated tops are incompletely coated with resin is difficult to resist, although all fibres examined appeared to be resin-coated over some portions of their length. The effective prevention of felting by an incomplete resin coating is more easily explained by a theory in which resin-treated portions of fibres adhere to one another under washing conditions [7], than by the alternative theory in which the resin, plus absorbed layers of water molecules, acts as a lubricant [8] .

Although resin-treated tops will normally be blended before yarns and fabrics are manufactured from them, and this will compensate for the unlevelness of treatment, the results revealed by the technique described here have important implications. For example, it is reasonable to assume that it would be possible to use a lower overall level of resin treatment if means were developed to ensure increased levelness of resin distribution. Also, it is probable that unlevel resin treatment gives rise to increased skitteriness in subsequent dyeing.

\section{RESIN DISTRIBUTION IN TREATED FABRICS}

A chlorine-Hercosett-treated woven fabric, after staining, is illustrated in Figure 4. Fluorescence was strongest at the fabric surface, and weakest in the interior of the fabric at yarn crossover points. Several yarns were removed from the fabric depicted in Figure 4 and one of the yarns is shown in more detail in Figure 5. The relative paucity of resin at yarn crossover points is clearly demonstrated. To show that the effect was not caused by uneven stain penetration, yarns were stained after removal from the fabric and the same pattern of fluorescent and non-fluorescent zones appeared.

In this study, the Hercosett resin was applied by padding to previously-chlorinated fabric. Since Hercosett is substantive to chlorinated fabric, even at room temperature, it was felt that this factor could have affected the results obtained; it was possible that the resin solution was exhausted before it reached the interior regions of the fabric. In order to investigate this aspect more fully, a similar unchlorinated fabric was treated by padding with Oligan SW, a shrink-resist resin which is effective on unchlorinated wool fabrics. Oligan SW was applied with a strongly cationic coreactant resin, Catalyst 3774 , which can be stained under the conditions used for staining Hercosett 57. Strictly speaking therefore, the technique used revealed the distribution of Catalyst 3774 on

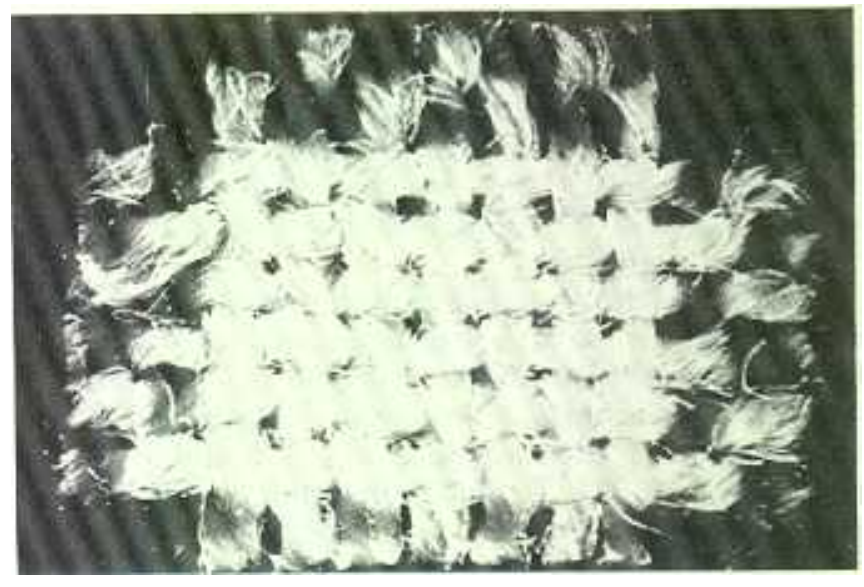

Figure 4 - FBA-staining pattern on chlorine-Hercosett-treated woven fabric showing weak fluorescence at yarn crossover points

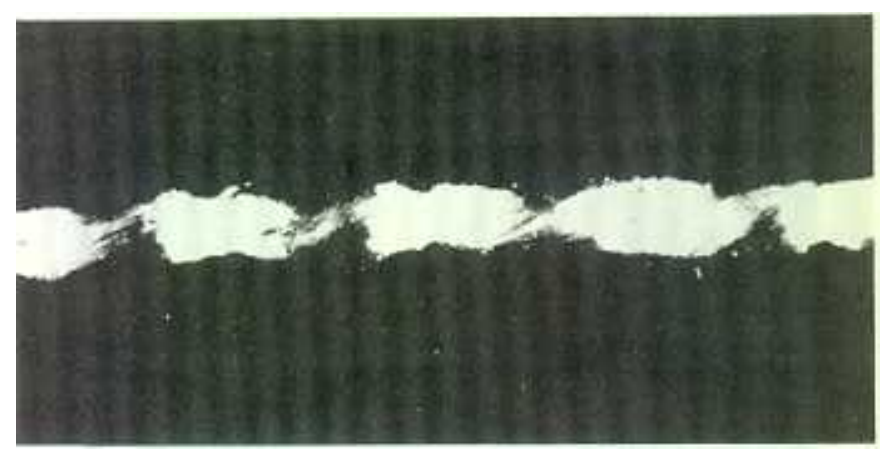

Figure 5 - Yarn removed from the fabric illustrated in Figure 4

the fabric, not the distribution of Oligan SW. However, Catalyst 3774 has a low affinity for unchlorinated wool, and it would be expected that the distribution of the two components of the resin system would follow the same pattern on the fabric. Figures $6 \mathrm{a}$ and $6 \mathrm{~b}$ illustrate the upper and lower surfaces of an Oligan SW-treated fabric which was dried horizontally at $40^{\circ} \mathrm{C}$. The slow drying of the fabric had apparently caused migration of the resin to the upper surface of the fabric, and the pattern of fluorescence in a yarn removed from this fabric (Figure 7) emphasizes this effect. Sections of fibre removed from the upper and lower faces of the fabric (Figures $8 \mathrm{a}$ and $8 \mathrm{~b}$ ) further emphasized the gross unevenness of resin distribution in this particular sample.

Examination of a fabric treated with Oligan SW under industrial conditions (dried in a multilayer tenter with an air temperature of $120^{\circ} \mathrm{C}$ ) showed better regularity of resin distribution, although there was some evidence of a low concentration of resin at the yarn crossover points. Figure 9 illustrates the fluorescence pattern in a section of stained fibre taken from this fabric. The fibre was found to be uniformly treated with resin along its entire length.

It appears, therefore, that there may be several possible reasons for unlevel distribution of resins in treated wool fabrics. In the case of chlorine-Hercosett-treated fabrics, either unlevel chlorination or lack of penetration of resin into the interior of the fabric may be responsible for the observed 

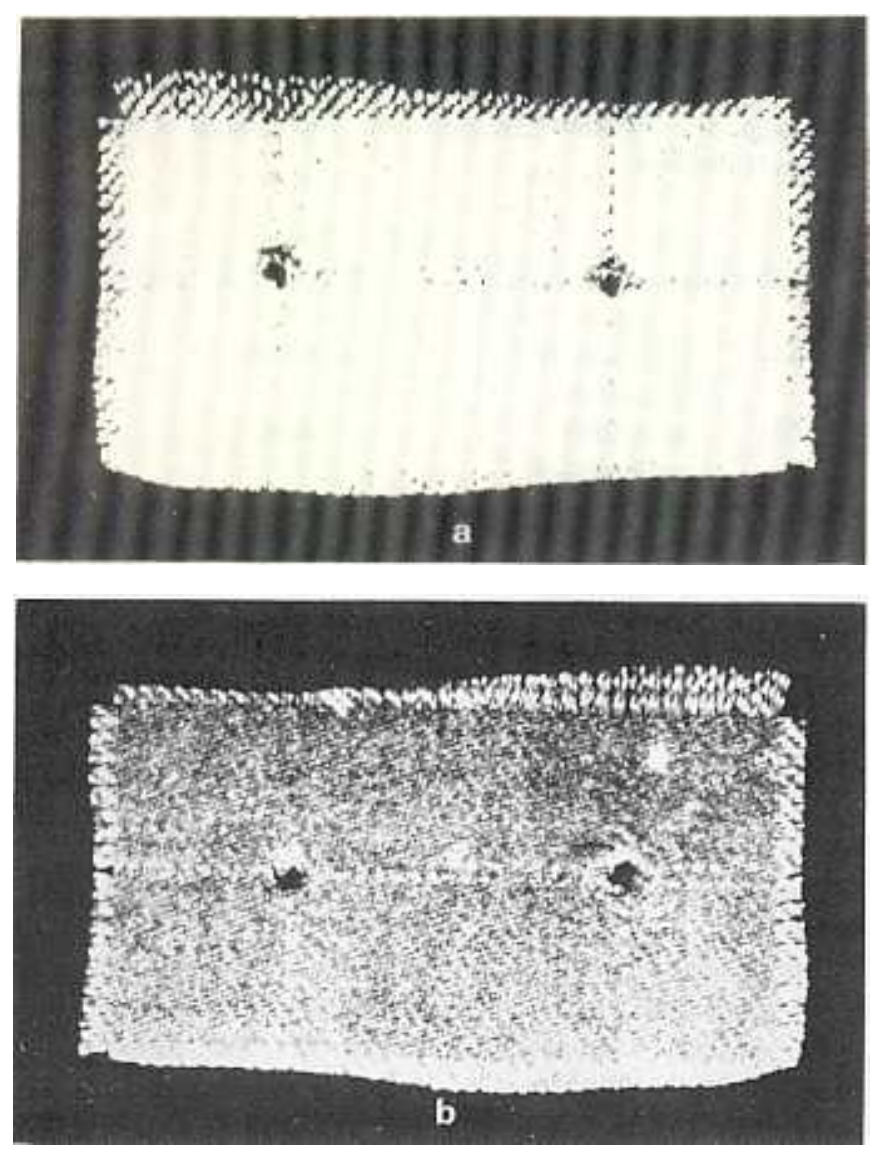

Figure 6 - FBA-staining pattern on Oligan SW-treated woven fabric dried at $40^{\circ} \mathrm{C}$ in a horizontal position. (a) upper surface and (b) lower surface of fabric

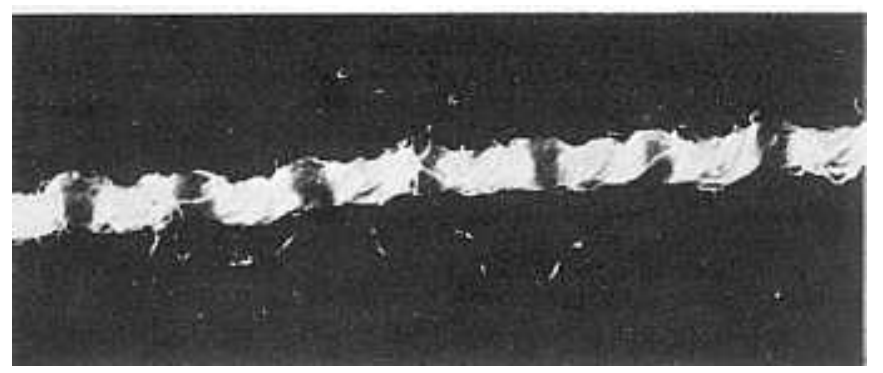

Figure - Yarn removed from the fabric illustrated in Figure 6

resin distribution. In Oligan SW-treated fabrics, migration of resin during drying appears to be a major cause of unlevelness. It is highly unlikely that the distribution pattern revealed in Figures 6 and 7 could be a direct result of irregularities in pad application. On the other hand, it is unlikely that Hercosett distribution on chlorinated fabric is influenced by migration, since it is known that the resin has a high affinity for chlorinated wool.

Whatever the reasons for unlevel distribution of resin in these fabrics, the fact that resin is located in higher concentration at the fabric surface, whilst the interior of the fabric at yarn crossover points is relatively undertreated, must have significant effects on the properties of the treated fabrics.
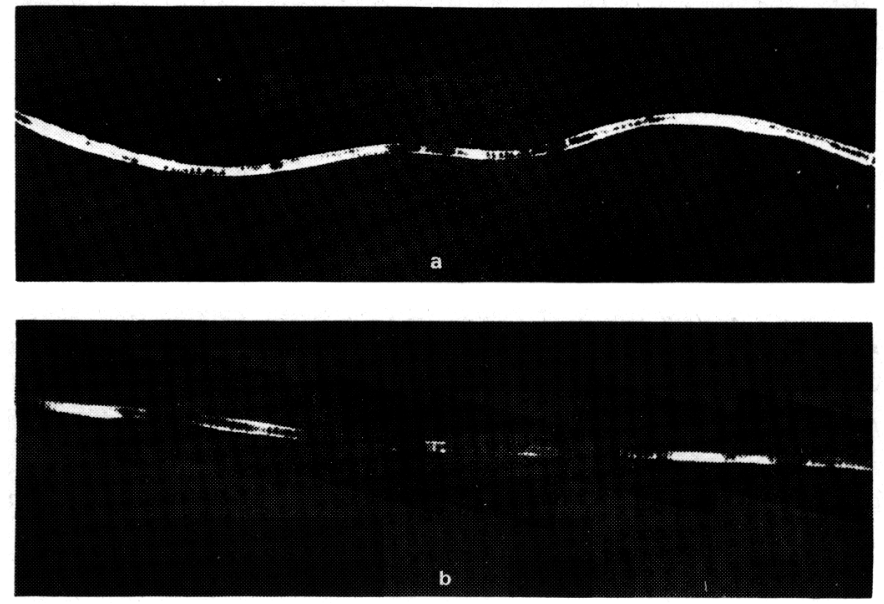

Figure 8 - Portions of single fibres removed from the fabric illustrated in Figure 6. (a) Fibre from upper surface and (b) fibre from lower surface of fabric

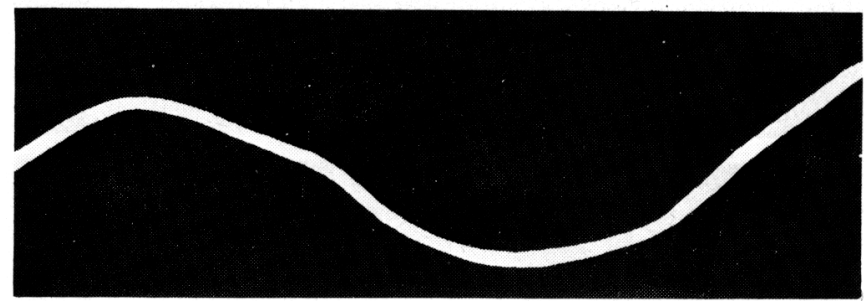

Figure 9 - Fluorescence pattern of fibre taken from an FBA-stained fabric treated with Oligan SW under industrial conditions

It seems probable that improvements in the handle of fabrics could be obtained if means were found to reduce the resin concentration at the surface, whilst general improvements in performance in washing and the physical properties of the fabric could be anticipated if a more even distribution of resin throughout the bulk of the fabric were possible.

An attempt was next made to determine the effects of varying chlorination conditions on the distribution of Hercosett resin in knitted Shetland fabric treated in a long liquor with both chlorine and resin. This is a widely-used industrial process for the production of Superwash knitwear. Samples were treated with $0.6 \%, 1.2 \%$ and $1.8 \% \mathrm{Cl}_{2}$ (o.w.w.) using the normal conditions of treatment, which are chosen to maximize levelness of chlorination. A further sample was treated with $1.2 \% \mathrm{Cl}_{2}$ under conditions chosen to give unlevel treatment. All the fabrics were treated with Hercosett from long baths containing $2 \%$ resin (o.w.w.). The results of staining the fabrics with FBA are illustrated in Figures $10 \mathrm{a}-\mathrm{d}$ and the distribution of resin on fibres taken from the fabrics is depicted in Figures 11a-d. At the lowest level of chlorination (Figures 10a and 11a) the fluorescence of the fabric surface was higher than at the two higher levels of chlorination, and the distribution of resin on individual fibres was uneven. Fabrics treated with $1.2 \%$ or $1.8 \%$ chlorine prior to Hercosett treatment were less fluorescent on the surface (Figures 10b and c), but fibres taken from these fabrics were much more evenly treated (Figures $11 \mathrm{~b}$ and $\mathrm{c}$ ). When chlorination was deliberately carried out in an irregular manner, subsequent 


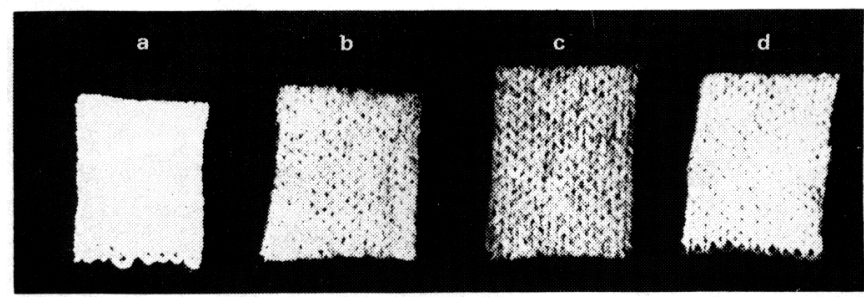

Figure 10 - Surface fluorescence pattern of FBA-stained Shetland fabrics treated by the batch chlorine-Hercosett process. (a) $0.6 \% \mathrm{Cl}_{2}, 2 \%$ Hercosett 57 , (b) $1.2 \% \mathrm{Cl}_{2}, 2 \%$ Hercosett 57, (c) $1.8 \% \mathrm{Cl}_{2}, 2 \%$ Hercosett 57 , (d) $1.2 \% \mathrm{Cl}_{2}$ applied under conditions chosen to give unlevel chlorination, $2 \%$ Hercosett 57.
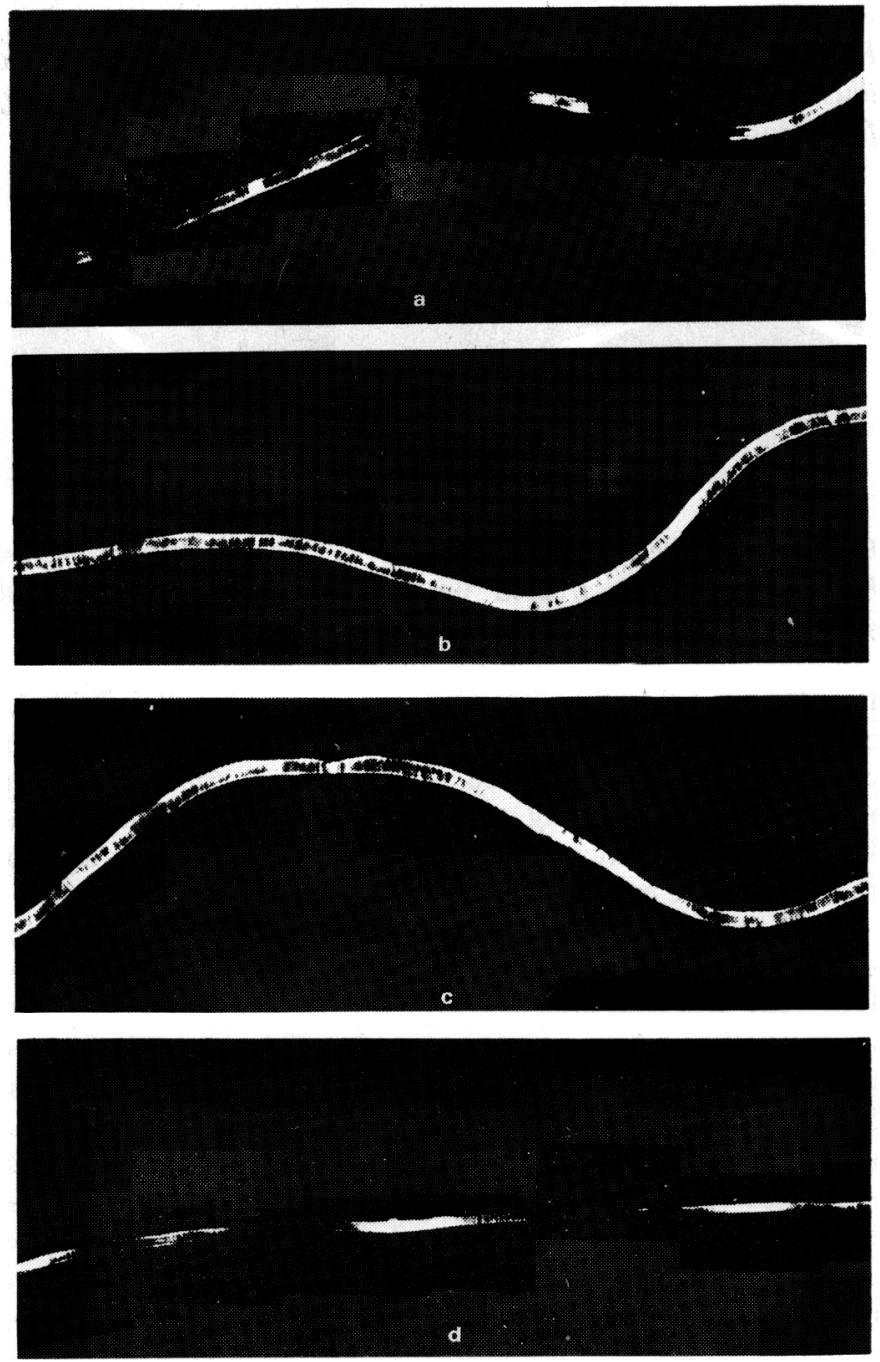

Figure 11 - Fluorescence pattern of fibres taken from the fabrics illustrated in Figure 10 (Fibre in Figure 11 a from fabric in Figure 10a, etc)

deposition of resin was confined almost exclusively to the fabric surface and individual fibres were very unevenly treated (Figures 10d and 11d). Shrinkage tests on the four fabrics showed that only the two fabrics on which regular resin

\section{TABLE 1}

Effect of Variations in the Chlorination Treatment on Washing Shrinkage of Fabrics Treated by the Batch Chlorine Hercosett Process
Chlorination treatment

Control (untreated)

$\begin{aligned} 0.6 \% \mathrm{Cl}_{2} & \begin{array}{l}\text { Conditions } \\ \text { chosen for } \\ \text { optimum } \\ \text { levelness of } \\ \text { treatment }\end{array} \\ .8 \% \mathrm{Cl}_{2} & \begin{array}{l}\text { Conditions } \\ \text { chosen to give } \\ \text { unlevel } \\ \text { treatment }\end{array}\end{aligned}$

$\begin{array}{cc}\text { Resin } & \text { Area } \\ \text { distribution } & \text { shrinkage }(\%)\end{array}$
$(\%)$

Unlevel
Level
Level
Unlevel

\section{distribution was achieved had a high level of shrink-resistance} (Table I).

These results are consistent with the theory that the major factor governing the evenness of distribution of resin in the batch chlorine-Hercosett process is the levelness of chlorination. It appears that completely level chlorination cannot be achieved, even under optimum treatment conditions, and that the exterior of a fabric will always receive more chlorine than the interior. With the two higher levels of chlorination used here, this was of little consequence, because almost all parts of all fibres received a sufficient level of chlorination to ensure affinity for the Hercosett resin, and the result was a regular distribution of resin throughout the fabric structure. At the lowest level of chlorination examined, however, only the most readily accessible surface layers of the fabric received sufficient chlorination, and the resin was deposited preferentially in these regions, leaving the interior virtually untreated. An excess of Hercosett was therefore available, so the deposit of resin on the fabric surface was heavier than in the case of fabrics treated with higher chlorine dosages. These circumstances were even more pronounced in the fabric which was treated unevenly with an intermediate concentration of chlorine, and the resultant resin distribution was even more unlevel.

\section{Conclusions}

The technique described here, in which an anionic fluorescent brightening agent is used as a stain to reveal the distribution of Hercosett resin on wool, should prove to be a useful diagnostic tool in process development, as well as a useful quality-control test.

The contrast obtained, after staining, between resin-treated and untreated portions of fibres, yarns and fabrics is very high, and the method is sufficiently sensitive to reveal, under the microscope, the distribution of resin on single fibres. One of the limitations of the method is that it cannot be applied to samples dyed to deep colours, but the depth of colour which can be tolerated is deeper than with staining techniques employing a non-fluorescent dye. Samples already treated with 
fluorescent brightening agents cannot, of course, be tested directly, but it is usually possible to strip FBA from the wool before staining. Stripping of dyes from machine-washable wool to allow the staining method to be used with deep colours is not normally possible because of the high level of fastness to which wool for this end-use is dyed.

A further limitation of the method arises from the fact that cationic softeners are also stained by the anionic fluorescent brightener under the conditions described. The use of such softeners on Hercosett-treated wool has become increasingly prevalent during the last year or so, but they can readily be stripped from the wool by Soxhlet extraction with chloroform for $3 \mathrm{~h}$. Where there are grounds for suspicion that cationic softeners are present in the wool, this procedure is recommended, and comparisons of the appearance of stained samples before and after extraction will confirm whether or not a cationic softener was present.

The results obtained by use of the new staining technique demonstrate the unlevelness of resin distribution to be found in wool treated with shrink-resist polymers. The dependence of Hercosett resin distribution on the levelness of chlorination carried out as a pretreatment is also emphasized.

It is hoped to extend this work to include a study of the distribution of anionic resins on wool, using a cationic fluorescent brightening agent. It may also be possible to study nonionic resins by the use of a fluorescent brightener with the right combination of staining properties, and by careful control of staining conditions (temperature, $\mathrm{pH}$, concentrations, time, etc.).
The authors thank the International Wool Secretariat for financial support and Dr K. R. F. Cockett of IWS for supplying chlorine-Hercosett-treated fabrics and tops. They also thank the IWTO Technical Committee and IWS for permission to publish this work.

(MS. received 11 March 1976; revised $M S$. received 23. June 1976)

\section{References}

1. Marsh, 'Self-Smoothing Fabrics' (London: Chapman \& Hall, 1962).

2. Miro, Tura, Canizar, Burkitt and Heap, Text. Chem. Colorist, 4 (1972) 271.

3. Feldtman and McPhee, Textile Manuf., 93 (1967) 22.

4. International Wool Secretariat, Superwash Process Manual.

5. Anderson, Katz, Lipson and Wood, Text. Research J., 40 (1970) 29.

6. Anderson, Goldsmith, Katz and Wood, Applied Polymer Symposia, No. 18 (1971) 715 .

7. Makinson and Lead, Text. Research J., 43 (1973) 669.

8. Kamath, 168th National Meeting, American Chemical Society, Sept. 1974, Reported in Sources and Resources, 7 (7) (1974) 40. 